\title{
Configurações
}

Revista de sociologia

\section{Morte em fronteiras: jovens "matáveis" nos celeiros da política e da cidade}

Death on border: young "killable" in the barns of politics and the city

Mort à la frontière : les jeunes "killable" dans les granges de la politique et de la ville

\section{Geovani Jacó de Freitas, Glaucíria Mota Brasil e Rosemary de Oliveira Almeida}

\section{(2) OpenEdition}

\section{Journals}

\section{Edição electrónica}

URL: http://journals.openedition.org/configuracoes/1509

DOI: 10.4000/configuracoes.1509

ISSN: 2182-7419

\section{Editora}

Centro de Investigação em Ciências Sociais

\section{Edição impressa}

Data de publição: 1 Dezembro 2012

Paginação: 165-184

ISBN: 1646-5075

ISSN: 1646-5075

\section{Refêrencia eletrónica}

Geovani Jacó de Freitas, Glaucíria Mota Brasil e Rosemary de Oliveira Almeida, « Morte em fronteiras: jovens "matáveis" nos celeiros da política e da cidade », Configurações [Online], 10 | 2012, posto online no dia 17 fevereiro 2014, consultado o 24 abril 2019. URL : http://journals.openedition.org/ configuracoes/1509; DOI : 10.4000/configuracoes.1509

Este documento foi criado de forma automática no dia 24 Abril 2019. 


\section{Morte em fronteiras: jovens "matáveis" nos celeiros da política e da cidade}

Death on border: young "killable" in the barns of politics and the city

Mort à la frontière : les jeunes "killable" dans les granges de la politique et de la ville

Geovani Jacó de Freitas, Glaucíria Mota Brasil e Rosemary de Oliveira Almeida

\section{Introdução}

1 O artigo integra análises e discussões acerca da violência urbana, com base em resultados de pesquisa cartográfica realizada na quinta cidade brasileira, Fortaleza, capital do Estado do Ceará. Teve como objetivo formatar um documento mediante a construção de um banco de dados, contendo informações estatísticas e mapas o mais abrangentes possíveis, que possibilitasse cartografar as ocorrências criminais e violentas nos espaços da cidade, visando a produção de perfil preciso deste fenômeno no Município.

2 A pesquisa teve como referência cinco categorias criminais extraídas dos dados brutos das ocorrências policiais mais recorrentes nas estatísticas gerais dos três anos da série histórica estudada (2007 a 2009), no sentido de direcionar empiricamente o "mapeamento para os nichos de criminalidade e violência mais representativos na cidade de Fortaleza, a saber; mortes violentas (homicídios, lesão corporal seguida de morte, infanticídio, aborto provocado e/ou induzido, suicídio, induzimento ao suicídio, morte no trânsito, outras mortes acidentais e outros crimes contra a vida); lesão corporal (ofensa à integridade corporal ou à saúde de outrem); roubos (subtração do bem segurado mediante grave ameaça ou violência à pessoa); furtos (difere do roubo por ser praticado sem emprego de violência contra a pessoa ou grave ameaça); relações conflituosas (calúnia, difamação, injúria, ameaça, preconceito de raça ou cor, rixa etc.). No caso dos homicídios, além da 
localização cartográfica, o banco de dados apresentou cruzamentos dos dados das vítimas com relação a sexo, idade, estado civil, escolarização e ocupação, a partir do qual se analisou o perfil das vítimas e o uso da arma de fogo como instrumento mais utilizado nos homicídios. Foram mapeados localidades, bairros e ruas, no que concerne os dados sobre declínio, estabilização e crescimento das ocorrências criminais.

No presente artigo, o nosso estudo volta-se para os homicídios e a associação destes com os territórios e espaços sociais estigmatizados de Fortaleza, instigando-nos a perguntar quem são as vítimas, que vetores e como estes influenciam nas ocorrências e por que acontecem em determinadas lugares com certa regularidade. Neste sentido, destacamos dois aspetos que orientam a compreensão do fenômeno: primeiro, os homicídios, em sua maioria, concentram-se em bairros localizados nas regiões periféricas da cidade, onde os investimentos públicos e de infraestrutura urbana são precarizados; segundo, nesse cenário os jovens emergem como vítimas preferenciais das ocorrências de homicídios, uma vez que constituem mais da metade do total de vítimas na cidade, sendo em maior número homens, solteiros e de baixa escolaridade e de cor parda ou negra. Esta constatação nos induz a pensar as representações sobre as práticas e relações que se estabelecem entre os crimes violentos (homicídios), os espaços onde eles ocorrem e as vítimas, levando-nos a refletir acerca das possíveis conexões de sentido que culminam na produção de sistemas classificatórios sobre a cidade e seus habitantes. Sem esquecer que se trata de espaços de conflitos e disputas que envolvem interesses privados e públicos e, portanto relações de força e poder que operam na gestão destes espaços.

Desta maneira, aqui, o eixo de discussão é a inserção da população jovem nas estatísticas de homicídio e tem como quadro de referência a análise do que se denomina de espaços urbanos estigmatizados, embaralhados e demarcados por fronteiras porosas. São questões ancoradas em discussões sobre estigma territorial, sujeição criminal, estado de exceção, de onde se discutem espaços de vida e de morte e políticas públicas enveredadas nessa cidade fronteiriça, que se constitui por relações de poder tecidas em redes que se operam por práticas formais e informais, legais e ilegais, lícitas e ilícitas e, portanto, demarcada por "fronteiras borradas".

5 A violência e a criminalidade urbanas, com destaque para os homicídios, são fenômenos cada vez mais visibilizados pelo crescimento do número de ocorrências criminais efetivas. Embora sejam representados como evento difuso, os dados do estudo revelaram seu caráter seletivo em relação a territórios, espaços, temporalidades e perfil das vítimas.

\section{A cidade e suas fronteiras: territórios estigmatizados e embaralhados}

6 Fortaleza registrou, em 2010, segundo IBGE, uma população de 2.447.409 habitantes, dado que revela explosão populacional da cidade verificada nas últimas duas décadas. É uma cidade em crescimento expressivo, configurando-se no campo urbano como metrópole em franco desenvolvimento. Todavia, tanto o crescimento populacional da cidade quanto a dinâmica do seu desenvolvimento não se deram de forma sustentada. Expressão disto é a expansão urbana desordenada e elevada concentração de renda que marcam o espaço urbano de Fortaleza ou a desigualdade social que apartam ricos e pobres na quinta maior capital do Brasil. 
7 A cidade divide-se entre rotas de expansão e desenvolvimento, por um lado, com a migração de novos empreendimentos públicos e privados, serviços, condomínios fechados de alto padrão, os quais marcam os bairros situados mais a leste, e pela ocupação desordenada e alta concentração populacional, mais a oeste da cidade, sem planejamento e intervenção prévios por parte dos poderes públicos. Este processo culmina com a precarização desses espaços em relação à moradia e investimentos em infraestrutura, transporte público, entre outros serviços essenciais, afetando, deste modo, amplas camadas populares da Capital, fato indistinto do quadro social das demais metrópoles brasileiras.

8 A concentração de renda e as desigualdades sociais decorrentes refletem-se, também, na distribuição dos homicídios nos espaços urbanos de Fortaleza. A Cartografia da Violência e da Criminalidade demonstra isto. A maioria dos assassinatos concentra-se em alguns bairros da periferia da cidade, em geral, aqueles demarcados nas regiões menos servidas de infraestrutura e serviços urbanos, em contraposição àqueles bairros considerados bem servidos, situados na região "nobre" da cidade.

9 Este quadro, no entanto, precisa ser visto com visão apurada, pois no campo dos estudos sobre violência, é pertinente analisar criteriosamente a situação de violência e crime nos rincões de pobreza espalhados nas periferias das metrópoles, tendo em vista, como afirma Vera Telles, "nossa velha e persistente, nunca superada, criminalização da pobreza". Diz, ainda, a autora ao se referir à questão:

Esse é um terreno minado, carregado de pressuposições e lugares-comuns que estabelecem a equação fácil e rápida entre pobreza, desemprego, exclusão, criminalidade e morte violenta, equação que alimenta a obsessão securitária que, também ela, compõe o cenário urbano atual, da mesma forma como alimenta os dispositivos gestionários que mobilizam representantes políticos, operadores sociais, voluntários, agentes comunitários e também a pesquisa acadêmica (Telles, 2010; 14).

10 A autora critica a análise da cidade relacionada apenas ao espaço urbano no mundo globalizado, por onde atravessam os equipamentos e produtos da cidade "legal" provenientes do mercado e do consumo globais, que atingem em cheio a vida social e nos fazem discutir a exclusão, o mundo do trabalho formal, desemprego, etc. Ela sugere uma abordagem expansiva sobre essas categorias, ao entender que estamos nas fronteiras do legal e ilegal, sendo a cidade, portanto, atravessada de ilegalismos que também passam pelos circuitos informais da economia, "o chamado comércio de bens ilícitos e o tráfico de drogas (e os seus fluxos globalizados), com suas sabidas (e mal conhecidas) capilaridades nas redes sociais e nas práticas urbanas" (Telles, 2010;13).

11 A cidade é um cenário multifacetado de práticas embaralhadas entre legalismo e ilegalismo, de trabalho formal e informal, de práticas lícitas e ilícitas executadas por diferentes sujeitos sociais, onde cresce a vida social e seus afazeres diversificados, a pobreza e a violência. Neste cenário se misturam práticas, visto que, da mesma forma que o trabalhador formal segue seu percurso de trabalho legal, ao mesmo tempo pode envolver-se em trabalhos ilícitos, tais como roubos e furtos, tráfico de drogas ou pirataria, em busca de outra renda. Ou, da mesma forma que um agente do estado proporciona vigilância e controle na venda de produtos ilícitos, ao mesmo tempo pode também aceitar suborno para não exercer controle algum. Ou, ainda, um líder comunitário de instituição não-governamental pode trilhar seu caminho do trabalho comunitário legal, mas também atravessado por ilegalismos na obtenção de verbas e equipamentos para execução de 
projetos sociais. Enfim, a ideia é que a compreensão da cidade, da pobreza e da violência não passa por modelos de análise que polarizam as questões sociais, mas por um embaralhamento entre as fronteiras do legal e ilegal que focam as tramas da cidade e da violência.

Desta forma, os paradoxos que opõem e distinguem os diferentes espaços da cidade incidem, também, em diferentes formas de expressão e de compreensão tanto da cidade quanto das práticas criminosas que a permeiam e cercam. É verdade que as estatísticas de homicídios ocorrem em maior número na periferia de Fortaleza, como atestou a Cartografia ${ }^{2}$, remetendo quase sempre para uma análise dual sobre pobreza e violência, o Estado e suas instituições de controle, a exclusão e inclusão social. Mas também é verdade que as análises atravessam as tramas incertas da experiência cotidiana de homens e mulheres que não se explicam apenas pela polarização da questão social, mas nas interfaces das práticas diárias de diferentes sujeitos, que são atravessadas por tantas outras práticas legais e ilegais, como assinaladas antes.

Assim, a correlação que analisamos não se passa entre pobreza e violência, mas entre violência e desigualdade social, na medida em que nem todos os bairros pobres apresentaram dados elevados de homicídios, e nem todos os bairros ricos ficaram isentos desse tipo de registro. Entretanto, o que nos parece relevante é o modo como expectativas coletivas são construídas quando referidas a esses espaços distintos, ao atribuírem aos bairros pobres a inexorabilidade e a naturalização de relações violentas como o homicídio, e aos bairros considerados ricos a sacralização de seus espaços e habitantes. Os sentidos desta produção simbólica serão discutidos a seguir.

Um dado inicial para essa análise é o de entendermos o sentido que as cidades contemporâneas assumem no processo de distinção social. Com efeito, as cidades configuram atualmente o problema dos estigmas territoriais, que culmina com um processo de marginalização avançada das camadas mais pobres.

\section{Para Wacquant o estigma territorial}

apresenta uma tendência distinta em conglomerar-se e aglutinar-se em torno de áreas 'barras-pesadas' 'proibidas', que são claramente identificadas - não só por quem é de fora, mas por seus próprios residentes - como antros urbanos em privação, imoralidade e violência, onde apenas os párias suportariam viver (2005: 195).

16 Em Fortaleza os bairros classificados como "violentos" ou "barras-pesadas" são carregados desses estigmas. Os pobres urbanos são duplamente estigmatizados. São classificados como "os outros", também como "incultos e perigosos", marcando profundamente nova forma de sociabilidade e de conflitualidade.

Situação emblemática foi analisada por Barreira et al. (1999a), sobre a juventude de Fortaleza, quando observaram um tipo de "linha imaginária" possível de defini-la a partir de uma importante avenida em Fortaleza ${ }^{3}$, que delimita o "lado de cá" e o "lado de lá" da cidade. Essas classificações segregam e delimitam espaços, como conhecidos ou desconhecidos, seguros ou inseguros.

A "territorialização" ou delimitação do "campo" configura o facto de jovens residentes em áreas nobres e ricas da cidade não passarem para o "lado de lá", nem os jovens do "lado de cá" passarem para o "lado de lá", pelo fato de não conhecerem as "regras", "códigos" e "protocolos", recebendo a classificação de "áreas perigosas". As classificações de "áreas perigosas" configuram os estigmas e as barreiras sociais que são fruto dessas representações realizadas sobre os espaços sociais. 
19 Nesse plano, é interessante analisarmos o aspeto simbólico da violência, ocorrendo um "casamento" entre a violência instrumental e a cognitiva, como afirma Machado da Silva, (2004) sobre o sentido da violência urbana:

[...] uma construção simbólica que destaca e recorta aspetos das relações sociais que os agentes consideram relevantes, em função dos quais constroem o sentido e orientam suas ações. Desta perspetiva possui um significado instrumental e cognitivo, na medida em que representa, de maneira percebida como objetivamente adequada a determinadas situações, regularidades de fato relacionadas aos interesses dos agentes nestes contextos. Mas, como toda representação, a violência urbana é mais do que uma simples descrição neutra. No mesmo movimento em que identifica relações de fato, aponta aos agentes modelos mais ou menos obrigatórios de conduta, contendo, portanto, uma dimensão prático-normativa institucionalizada que deve ser considerada (2004: 58).

20 A violência urbana é instrumental, objetiva e cognitiva, pois revela interesses e sentidos emitidos por seus agentes ao usarem a força como instrumento adequado em determinadas situações, mas é, antes de tudo, uma representação, uma expressão simbólica que constrói subjetivamente certo ordenamento de determinados espaços e pessoas, formas de conduta e classificações como fatores de organização das relações sociais. Esta análise possibilita importante visão sobre territorialização e o estigma classificatório do bairro pobre, ganhando destaque a denominação do bairro como violento, representado por seus próprios moradores. No caso de Fortaleza são os bairros mais a oeste da cidade, aqueles situados nas denominadas fronteiras da cidade, mais especificamente os que fazem fronteira com a Região Metropolitana, os quais, acabam também por concentrar elevados índices de vulnerabilidade social.

Outro aspeto importante no interior dos espaços urbanos é a relação entre a construção dos estigmas e a questão da insegurança urbana, gerando uma "cultura do medo", fortemente ancorada no aumento estatístico da violência e da criminalidade. A cultura do medo pode ser compreendida no interior desse "ciclo vicioso" que foi criado: violência gerando medo e medo gerando violência.

\section{Violência urbana: medos que se contam}

A vida urbana, hoje, é experimentada sob o signo da violência e do medo. A cidade, na contemporaneidade brasileira, deixa de ser, à primeira vista, o lugar da proteção para ser o do perigo. Esta nova qualidade assumida pela cidade é oposta ao próprio conceito de cidade, historicamente falando.

As cidades atuais, no Brasil, parecem estar na contra mão desta assertiva histórica. Elas retomam os muros, só que, desta feita, não mais para se proteger do inimigo externo. Os muros são construídos internamente, criando cidades dentro de uma mesma cidade, o que Tereza Caldeira (2008) denomina de "cidade dos muros". Os muros, neste caso, continuam com as suas funções de proteção, mas não dos inimigos de fora, mas os da própria cidade. De espaço de segurança e proteção a cidade tornou-se espaço da insegurança e de medo.

As representações sobre a cidade e a violência urbana têm fundamentação objetiva na medida em que se revelam estatísticas oficiais de dados de violência; entretanto, elas também são produtos de uma construção simbólica e do medo socialmente construídos tanto pelas experiências efetivas dos moradores, quanto pelas narrativas criadas em torno dos fatos violentos e, sobretudo, pela ação mediática. As estatísticas do crime 
contribuem para hierarquizar espaços violentos em relação a outros não violentos. De acordo com o relatório apresentado, em março de 2012, pelo Observatório de Segurança da OEA, o Brasil é o país com maior índice de homicídios dolosos do continente americano, à frente de Colômbia, México e Estados Unidos. 0 relatório destaca que, em toda a região, ocorreram 154.836 homicídios em 2010, com média diária de 424 registros ou 17 a cada hora. Deste total 75\% foram cometidos com armas de fogo. O Brasil lidera os casos de homicídios dolosos, com 40.974 assassinatos em 2010 para uma população de 190 milhões de habitantes; em segundo lugar está a Colômbia, com 29.324 homicídios para uma população de 46 milhões de habitantes; em terceiro lugar segue-se México, com 20.585 para uma população de 112 milhões; e, em quarto, os Estados Unidos, com 14.159 assassinatos para uma população de 308 milhões (http://www.oas.org).

Com relação à Fortaleza, os dados da Cartografia revelam o crescimento da violência, na série histórica analisada em 2007, 2008 e 2009, a qual corresponde respetivamente 844 homicídios (35,14 por $100 \mathrm{mil} / \mathrm{hab}$ ); 823 (33,68 por 100mil/hab.) e 937 (37,82 por $100 \mathrm{mil} /$ hab.). Este cenário tem revelado uma cidade marcada pelo signo crescente da insegurança. Embora a violência seja crescente e se mostre difusa, na medida em que atinge objetiva e simbolicamente todos os espaços da cidade, na verdade tem um caráter marcadamente seletivo.

Há espaços que, mesmo tomados pelo medo, requerem para si o sentido de espaços não violentos. Prova disto é o efeito surpresa quando algum evento considerado violento ocorre nesses espaços, extraindo das narrativas sobre a cidade o efeito surpresa, tais como "até na Aldeota, até no Meireles, até no Iguatemi...".

Por outro lado, de acordo com Vera Telles (2011), é a pequena criminalidade difusa e avulsa que tem alimentado os medos urbanos e a insegurança,

ocasionado a demanda por mais punição e principalmente conferindo razão e aceitabilidade à multiplicação generalizada dos enclaves fechados e dos dispositivos privados de segurança e policiamento (2011:5).

Contudo, não podemos deixar de reconhecer que estamos convivendo com uma violência extremamente seletiva, cujo corolário atinge a população juvenil como suas vítimas preferenciais. De acordo com os dados nacionais e locais, mais como vítimas do que como vitimizadores.

\section{1 Jovens: inexoráveis vítimas}

Parte da narrativa sobre a cidade e seu cotidiano tende a romper com o significado de uma cidade protegida e segura para criar a sensação de uma cidade tomada pela violência, cuja probabilidade de se tornar vítima dela é igual para todos. Observamos, entretanto, que parte considerável dos homicídios tem como vítimas um segmento preferencial e profundamente marcado por questões de gênero e classe, constituído por jovens, do sexo masculino, pertencentes às camadas mais empobrecidas da sociedade e de baixa escolaridade no cruzamento dos indicadores de pertencimento geográfico com os dados colhidos pela Cartografia. Do ponto de vista da faixa etária, destacamos que $62 \%$ em média desses homicídios, em todas as Regionais de Fortaleza, têm como vítimas preferenciais jovens na faixa de 15 a 29 anos.

30 Em relação aos jovens, ao se tomar o parâmetro nacional é neste segmento populacional que se concentra a maior parte dos homicídios. O Mapa da Violência 2011, intitulado "os Jovens do Brasil", utilizou estimativas populacionais do IBGE para o ano de 2008 que 
indicavam um contingente de 34,6 milhões de jovens na faixa etária dos 15 aos 24 anos, representando $18,3 \%$ do total de habitantes projetados pelo IBGE para o País que era de 189,6 milhões.

31 Em relação à mortalidade de jovens, o Mapa ainda aborda números expressivos de vitimização da juventude. 0 documento dividiu a população "jovem" de 15 a 24 anos da "não jovem" de 0-14 e 25 e mais anos, obtendo os seguintes resultados:

Na população não jovem, só $9,9 \%$ do total de óbitos são atribuíveis a causas externas. Já entre os jovens, as causas externas são responsáveis por $73,6 \%$ das mortes. Se na população não jovem só $1,8 \%$ dos óbitos são causados por homicídios, entre os jovens os homicídios são responsáveis por $39,7 \%$ das mortes. (Waiselfi sz, 2011: 19).

Os dados acima demonstram que, no Brasil, continua a seletividade das vítimas de mortes violentas, dentre elas, os homicídios em relação aos jovens. Essa realidade foi confirmada pela Cartografia em Fortaleza, especialmente no item faixa etária. Os números indicaram elevado índice de homicídios contra jovens na cidade, quando comparados à população adulta, corroborando dados nacionais, como evidencia a tabela 1.

QUADRO 1 - HOMICÍDIOS POR FAIXA ETÁRIA (EM TERMOS ABSOLUTOS)

\begin{tabular}{ccccccccccc}
\hline \multirow{2}{*}{$\begin{array}{c}\text { Recorte } \\
\text { Geográfico }\end{array}$} & \multicolumn{8}{c}{ Homicídios por faixa etária (em termos absolutos) } \\
\cline { 2 - 10 } & Ano & $\begin{array}{c}\text { Até } \\
14\end{array}$ & $15-18$ & $19-24$ & $25-29$ & $30-39$ & $40-59$ & $\begin{array}{c}60 \\
\text { e }\end{array}$ & Ignor. \\
\hline \multirow{2}{*}{ Fortaleza } & 2007 & 18 & 115 & 269 & 138 & 166 & 105 & 17 & 16 \\
\cline { 2 - 10 } & 2008 & 13 & 115 & 245 & 149 & 162 & 99 & 19 & 22 \\
\hline & 2009 & 16 & 140 & 295 & 157 & 169 & 107 & 13 & 40 \\
\hline
\end{tabular}

FONTE: PESQUISA CARTOgRAfi A DA CRIMINALIDADE E DA VIOLÊNCIA NA CIDADE DE FORTALEZA, 2010.

Pelos dados da pesquisa concluiu-se que há concentração de mortes por homicídio entre os jovens na faixa etária de 19 a 24 anos nos três anos analisados; essa faixa etária é seguida da faixa de adultos com menos de 40 anos, ou seja, de 30 a 39 anos, aparecendo depois aqueles de 25 a 29. Outro aspeto relevante é que houve tendência de crescimento de homicídios entre os jovens nas três faixas etárias aqui descritas, não tão expressiva entre 2007 e $2008^{5}$, mas bem crescente em relação a 2009.

A pesquisa também concentrou as faixas etárias na seguinte sequência: menor que 15 , de 15 a 29 anos e maior que 29 , no sentido de visualizar melhor como os jovens, em fase produtiva, são as principais vítimas de homicídios em Fortaleza, como se pode observar na tabela 2.

QUADRO 2 - FAIXA DE IDADE 


\begin{tabular}{cccccccc}
\hline & & \multicolumn{5}{c}{ Faixa de idade } \\
\cline { 3 - 8 } Ano & $\begin{array}{c}\text { Total de } \\
\text { homicídios }\end{array}$ & \multicolumn{2}{c}{$<15$} & \multicolumn{2}{c}{15 a 29} & \multicolumn{2}{c}{$>29$} \\
\cline { 3 - 9 } & & Abs. & $\%$ & Abs. & $\%$ & Abs. & $\%$ \\
\hline 2007 & 844 & 18 & 2,13 & 522 & 61,85 & 304 & 36,02 \\
\hline 2008 & 824 & 13 & 1,58 & 509 & 61,77 & 302 & 36,65 \\
\hline 2009 & 937 & 16 & 1,71 & 592 & 63,18 & 329 & 35,11 \\
\hline
\end{tabular}

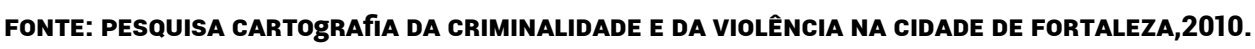

Os jovens nesta faixa etária, no ano de 2007, somaram $61,85 \%$ do total de homicídios em Fortaleza; de forma semelhante quantificaram $61,77 \%$ em 2008 e cresceram para 63,18\% em 2009. Trata-se de um perfil de mortes por homicídio na cidade de Fortaleza. A pesquisa ainda registrou vários dados, concluindo que as vítimas são, na esmagadora maioria, jovens homens e solteiros, além de possuírem baixa escolaridade.

QUADRO 3 - SEXO

\begin{tabular}{cccccc}
\hline \multirow{2}{*}{ Ano } & \multirow{2}{*}{$\begin{array}{c}\text { Total de } \\
\text { Homicídios }\end{array}$} & \multicolumn{2}{c}{ Masculino } & \multicolumn{2}{c}{ Feminino } \\
\cline { 3 - 6 } & & Abs. & $\%$ & Abs. & $\%$ \\
\hline 2007 & 844 & 804 & 95,2 & 40 & 4,8 \\
\hline 2008 & 824 & 783 & 95,0 & 41 & 5,0 \\
\hline 2009 & 937 & 886 & 94,5 & 51 & 5,5 \\
\hline
\end{tabular}

Como demonstrado na tabela 3 acima, dos 844 homicídios registrados em Fortaleza no ano de 2007, 40 são do sexo feminino e 804 são do sexo masculino o que corresponde a 95,2\% de homens vítimas; já em 2008, a realidade é semelhante, pois, dos 824 homicídios, 41 são mulheres e 783 são homens, equivalente a 95\% de homens; e em 2009, do total de 937 homicídios, 51 são mulheres e 886 são homens, o que corresponde a 94,5\%. Contudo, pode-se observar, ainda na tabela 3 , que, nos três anos, houve crescimento continuado do número de mulheres vítimas de homicídios.

QUADRO 4 - HOMICíDIOS POR ESCOLARIZAÇÃo (EM TERMOS ABSOLUTOS E \%)

\begin{tabular}{|c|c|c|c|c|c|c|c|c|c|}
\hline Ano & $\begin{array}{c}\text { Analf } \\
\mathrm{n} .^{\circ}(\%)\end{array}$ & $\begin{array}{c}\text { Alfab } \\
\text { n. }{ }^{\circ}(\%)\end{array}$ & $\begin{array}{c}\mathrm{EF} \\
\text { Inc. } \\
\mathrm{n}^{\circ}{ }^{\circ}(\%)\end{array}$ & $\begin{array}{c}\mathrm{EF} \\
\text { Com } \\
\mathrm{n} .^{\circ}(\%)\end{array}$ & $\begin{array}{c}\text { EM } \\
\text { Inc. } \\
n .^{\circ}(\%)\end{array}$ & $\begin{array}{c}\text { EM } \\
\text { Com } \\
\text { n. }{ }^{\circ}(\%)\end{array}$ & $\begin{array}{c}\text { Sup. } \\
\text { Inc. } \\
\mathrm{n}^{\circ}(\%)\end{array}$ & $\begin{array}{l}\text { Sup. } \\
\text { Com } \\
\mathrm{n} .^{\circ}(\%)\end{array}$ & $\begin{array}{l}\text { Ignor. } \\
\text { n. }{ }^{\circ}(\%)\end{array}$ \\
\hline 2007 & $42(4,98)$ & $329(38,98)$ & $231(27,37)$ & $86(10,19)$ & $35(4,15)$ & $58(6,87)$ & $12(1,42)$ & $4(0,47)$ & $47(5,57)$ \\
\hline 2008 & $31(3,76)$ & $308(37,38)$ & $237(28,76)$ & $97(11,77)$ & $30(3,64)$ & $58(7,04)$ & $6(0,73)$ & $8(0,97)$ & $49(5,95)$ \\
\hline 2009 & $40(4,27)$ & $333(35,54)$ & $314(33,51)$ & $65(6,94)$ & $19(2,03)$ & $47(5,02)$ & $23(2,45)$ & $7(0,75)$ & $89(9,50)$ \\
\hline
\end{tabular}

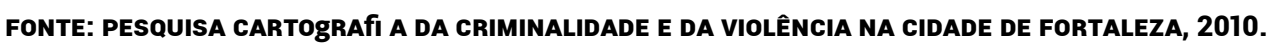

Quanto ao item escolaridade, como podemos ver na tabela 4, os dados demonstram baixa escolarização das vítimas de homicídios em Fortaleza. Os dados de 2007 a 2009 revelam 
concentração dos homicídios no item alfabetizados. Em 2007 houve 329 registros de vítimas nesta condição, ou seja, 38,98\% de 844 registros; foram 308 vítimas em 2008, correspondendo a $37,38 \%$ das 824 vítimas e, em 2009, contabilizados 333 vítimas, o equivalente a 35,54\% dos 937 casos de Fortaleza neste ano. Por outro lado, estes índices caem para quem possuía Ensino Superior Completo: foram 4 vítimas em 2007 (0,4\% do total); 8 vítimas em 2008 (0,9\%) e 7 em 2009 (0,7\% do total).

As características dos dados apresentados na tabela 4, dentre outras, compõem um quadro do caráter seletivo da violência fatal, ou das vítimas preferenciais em Fortaleza. São homens jovens das camadas populares, aqueles que podemos nominar, de acordo com Agamben (2002), de homo sacer ou "vida matável", aquela vida que pode ser exterminada sem que isso represente um crime. Segundo o autor, toda sociedade mesmo a mais moderna decide quem são seus "homens sacros" ou quais são as vidas matáveis. São nesses espaços que se constitui um "campo social de indiferenciação" entre práticas lícitas e ilícitas, "a norma e a exceção, o direito e a força." Portanto, são nessas zonas de fronteiras indefinidas que o jogo entre a "vida nua" (vida matável) e outras formas de vida (condições de "possibilidades e potências de vida") está sendo jogado. É isso que precisamos melhor compreender nas análises dos dados de criminalidade e violência do cotidiano societário como destaca Telles (2010).

Por outro lado, o aparecimento e a disseminação do uso e do tráfico de drogas têm causado impactos profundos na coreografia do crime em Fortaleza em função de seus efeitos devastadores sobre os usuários mais jovens, ampliando o contingente de "vidas matáveis". Isto implica dizer que a criminalidade tem atingido, principalmente, a população infanto-juvenil pobre. Aquela parcela sem perspetivas de inserção no mercado de bens de consumo via políticas de inclusão como educação, lazer, cultura, trabalho e renda; jovens pobres tornam-se vulneráveis duplamente: são vítimas da globalização de valores consumistas e de padrões estéticos, sem que lhes sejam dadas as mesmas condições de oportunidades de trabalho e rendimento oferecidas a outras juventudes. Sendo desiguais em oportunidades e iguais em desejos estéticos e em libido social, tornamse presas fáceis do mercado do narcotráfico, seja como consumidor, seja como "trabalhador" a serviço do tráfico e seus microarranjos, cujo corolário é o mundo do crime e da autoeliminação. Tornam-se vítimas dessa indústria, de modo triplamente afetados: a) como usuários, sucumbem biologicamente pelo uso da droga; b) como vítimas fatais da guerra urbana engendrada por este mercado; e c) como vitimizadores.

Assim posto, emerge o cenário propício para maior envolvimento da população jovem com a violência, mais no papel de vítima preferencial do que como vitimizadora. Mesmo assim, os jovens acabam por ser classificados como "classe perigosa".

41 Na contramão da violência seletiva está o desafio da elaboração de políticas públicas de segurança focadas e eficazes no enfrentamento dessa problemática.

Estas dizem respeito às mudanças das práticas criminosas na cidade decorrentes da dinâmica e dos interesses do crime organizado, sobretudo dos impactos da circulação e consumo do crack e, mais recentemente, do cristal e do oxi, envolvendo a juventude da cidade, em especial os jovens pobres. Este aspeto, se não tão novo assim, tem impactado na capacidade de gestão das políticas públicas governamentais (e não governamentais), sobretudo as de segurança urbana, centradas nas atividades de inteligência dos dispositivos policiais, nas suas práticas de mediação de conflitos e de articulação 
institucional com outros setores do sistema público, como educação, cultura e saúde pública.

43 A assertiva da necessidade de políticas sociais é facto e discurso corriqueiro alavancada no campo da política, no que diz respeito ao tratamento da violência e, em especial, quando atinge as populações jovens. Entretanto, a política não se configura mais como a promessa de transformação aludida pela crítica social levantada pelas promissoras lutas sociais das décadas de 1970 e 1980 no Brasil. Na contemporaneidade, como diz Vera Telles (2010), a política tem-se mobilizado na tentativa de gerir urgências e riscos sociais mediante políticas públicas que se reduzem a programas emergenciais e geralmente evasivos voltados para os pobres em suas mais diversas necessidades e inserções. No campo da violência e do mundo das drogas a conotação não difere muito. Seria essa uma "nova biopolítica" da "governamentalidade" das cidades?

Gestão dos "riscos" de um social não mais declinado na gramática dos direitos e garantias sociais, de que a proliferação de dispositivos de ajuda social e a ativação do discurso humanitário são evidências tangíveis. Primado das urgências - econômicas, militares, humanitárias, sociais, ecológicas, em todas uma lógica que parece mimetizar e desdobrar a lógica da financeirização do capitalismo contemporâneo (Telles, 2010: 67-68).

Apoiada pelo discurso da urgência e do humanismo, as políticas sociais, em especial, aquelas voltadas para jovens em situação de vulnerabilidade social, conflito com a lei, entre outras configurações, passam a ser compensatórias. Ao invés da política tradicional do enfrentamento e da crítica social, o discurso político se volta para análises fragmentadas e práticas focalizadas e seletivas de um "público-alvo" juvenil patológico, necessitado, portanto, de compensação social. Nesta conceção, ao jovem em situação de pobreza, vulnerabilidade social e criminalidade, urge intervenção social, mas não do ponto de vista de políticas ditas universais que visam intervenções para mudanças efetivas na qualidade de vida dos sujeitos, mas se trata de:

Intervenção social, intervenção cultural, intervenção sanitária, intervenção humanitária, também intervenção policial e intervenção militar: nas peculiaridades de cada campo de atuação, é uma mesma lógica, gestão dos riscos, sempre pontual, territorialmente definida, porém sempre deslocante, conforme se redefinem os alvos, os focos, os problemas. (ibidem: 157-158).

No que se refere à intervenção policial nas cenas juvenis de envolvimento com a criminalidade, percebemos os esforços dos gestores na área das políticas de segurança urbana, nos termos colocados por Vera Telles. O facto é que, além da intervenção fragmentada, nos deparamos com a falta de preparo das organizações policiais em geral, associada às condições de trabalho precárias, seja em termos de qualificação técnica, seja na formação e operacionalização das forças policiais, seja, ainda, na própria organização institucional, extremamente militarizada, cujo entendimento é do combate ao inimigo. $\mathrm{Ou}$, ainda, pelas práticas seletivas da polícia na identificação do suposto tipo social criminoso ou do que Michel Misse denomina de "sujeição criminal", processo pelo qual são identificados previamente os supostos sujeitos que irão compor um tipo social, cujo caráter é socialmente considerado "propenso a cometer um crime" (2008: 14). Essas são questões que têm contribuído para que o sistema de segurança pública e suas organizações também façam parte da cena violenta urbana.

Por outro lado, não se ignora que as "relações perigosas" envolvem também os "homens da lei", aqueles que têm o dever e a obrigação legal de fazer cumprir a lei (a quem foi delegado o poder discricionário de matar e não matar, de deixar matar e não deixar 
matar), caracterizando assim o que afirmamos antes como a porosidade das fronteiras entre as práticas legais e ilegais, lícitas e ilícitas que envolvem os dispositivos de controle e manutenção da ordem nesses espaços da cidade.

Os bairros classificados como mais violentos têm uma população que se ressente de políticas públicas de inclusão social, capazes de inverter a situação de abandono em que vive a maioria dos moradores dessas áreas. A polícia, quando aparece, muitas vezes, não é com ações preventivas ao crime, nem de mediação de conflitos. Aparece como parte da própria violência. Aqui, não se desconhece a violência policial, assim como a participação de policiais nas microilegalidades na gestão da ordem nesses espaços da cidade, nas práticas criminosas que envolvem os "negócios" da vida e da morte. Nesses bairros, podese descrever e fazer a etnografia das práticas policiais, sejam elas legais e ilegais, de suas intervenções e procedimentos junto às populações mais vulneráveis ou junto aos segmentos ditos criminosos. Assim, como não ignoramos que estes são espaços

em que a presença do Estado afeta as vidas e as formas de vida, circunscreve-se um campo de práticas no qual os sujeitos fazem (e elaboram) a experiência da lei, da autoridade, da ordem e seu inverso, em interação com outros modos de regulação ancorados nas condições (Das e Poole apud Telles, 2011:5).

49 E, ainda, são espaços construídos pelas condições de possibilidades do mundo de vida dessas populações. Os moradores desses bairros violentos

também transitam entre o dentro e o fora do Estado, maquinam artifícios nas fronteiras incertas entre o legal e o ilegal, agenciam contracondutas, negoceiam regras, limites, protocolos em função das condições concretas de vida, em seus imperativos de sobrevivência, necessidades de segurança, sentidos de ordem e justiça (ibidem).

Pode-se dizer que, tanto a presença como a ausência do Estado afetam a vida das populações na sua racionalidade de gestão da vida cotidiana citadina, principalmente, quando o Estado conhecido é o "estado de exceção". Ou podemos dizer como Agamben (2004), que o estado de exceção torna-se cada vez mais paradigma dos modos de dominação dos governantes ou dos modos de gestão dos seus dispositivos políticos nos Estados democráticos. Assim, o estado de exceção contemporâneo seria "uma tentativa de incluir na ordem jurídica a própria exceção, criando uma zona de indiferenciação em que facto e direito coincidem" (Agamben, 2004:.42). Ao situar o paradigma da exceção não se trata de defini-la como forma permanente de gerência do Estado, mas de perceber como este mesmo Estado, no mundo contemporâneo, se libera, muitas vezes, da gestão política estabelecida pelo "contrato social" ou pelo seu ordenamento jurídico e passa a gerenciar apenas as urgências, como administrador de políticas esfaceladas ou, como diz Vera Telles nas pegadas de Agamben, em um "permanente estado de urgência que derroga as regras dos direitos, implode os contratos, desestabiliza os acordos e, sobretudo, desativa o espaço da política..." (Telles, 2010:152).

51 A população jovem vulnerável atendida pela intervenção política da urgência e do risco permanece nos recantos da criminalidade nos bairros pobres da cidade, mas não de forma passiva. Assim, "a gestão dos riscos, intervenção e segurança, cria o seu fora, suas margens..." (Telles, 2010: 158). Dessa feita, "estados de exceção" do lado de lá da periferia surgem nos raios da violência vitimizando ou fazendo vítimas, mediados por mercados ilícitos de drogas e armas. Assim, vivemos numa cidade embaralhada pelas fronteiras pouco demarcadas entre legal e ilegal, lícito e ilícito. 
52 Por outro lado, os homicídios, na cidade de Fortaleza, como no Brasil, nos colocam uma série de questões, entre as quais as seguintes: o que eles significam para além da problemática da criminalidade e da violência? Que outros aspetos os influenciam, tornando complexa e difícil a explicação da prática da morte?

\section{Homicídios: aspetos e enfrentamentos}

Diante dos dados e análise até aqui empreendidos, algumas questões e características dos homicídios chamam nossa atenção. Primeiro, o facto de a prática do homicídio, mantido através do tempo e dos países, estar associado à baixa probabilidade de alguém ser assassinado por um desconhecido. Dos quase 50 mil homicídios ocorridos anualmente no Brasil, 90\% das suas vítimas mantinham algum tipo de relação com o homicida. Aproximadamente $90 \%$ dessas mortes envolvem homicidas primários e, portanto, são crimes sem história pessoal. A ONU tem classificado esta violência letal de interpessoal, resultante, portanto, de conflitos interpessoais.

Segundo, na cidade de Fortaleza, seguindo uma tendência nacional e acompanhando a classificação da ONU, os dados revelam que mais de 50\% dos homicídios ocorridos são atribuídos a motivos fúteis, entre conhecidos e nas proximidades da residência da vítima, o que demonstra que a população está se matando. Nesse sentido, indicador relevante refere-se aos dados aqui apresentados como resultado da série histórica da Cartografia em que $\mathbf{8 0 \%}$ dos homicídios de Fortaleza têm como objeto utilizado para a sua execução a arma de fogo, como demonstra a tabela 5.

QUADRO 5 - HOMICÍDIOS POR ARMA DE FOgO 2007 A 2009

\begin{tabular}{|c|c|c|c|c|c|c|c|c|c|}
\hline \multirow[b]{3}{*}{ Regional } & \multicolumn{9}{|c|}{ Anos } \\
\hline & & 2007 & & & 2008 & & & 2009 & \\
\hline & & 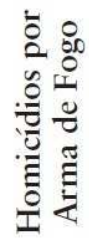 & $\%$ & 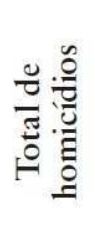 & 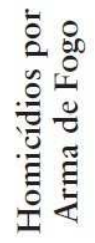 & $\%$ & 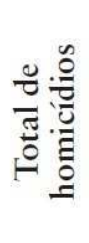 & 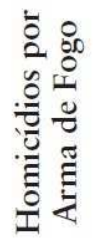 & $\%$ \\
\hline Fortaleza & 844 & 684 & 81,05 & 824 & 676 & 82,04 & 937 & $\stackrel{\infty}{\infty}$ & 86,24 \\
\hline
\end{tabular}

FONTE: PESQUISA dA CRIMINALIDADE E DA VIOLÊNCIA NA CIDADE DE FORTALEZA, 2010.

Terceiro, os dados da tabela 5 nos revelam que não só a população está armada, mas que o uso da arma de fogo na resolução dos conflitos é a maior das problemáticas, um dado fundamental que não pode ser desprezado porque altera completamente a sociabilidade entre as pessoas.

Quarto, o tráfico de drogas, associado ao facto de pessoas portarem armas e/ou terem acesso fácil a estas, é um complicador maior no dia a dia da sociabilidade desses espaços estigmatizados ou fora deles.

Os jovens estão armados, como constatamos antes, não são apenas os vitimizadores, são principalmente as vítimas nesse campo de disputa acirrada e, possivelmente, regido pelo signo "positivo" da arma como elemento de socialização e afirmação de sua illusio social. 
58 Em termos de diagnóstico e avaliação de políticas de segurança pública, estes aspetos revelam, entre outros importantes, que ações de mediação dos conflitos ou a sua prevenção, uma das tarefas dos órgãos de segurança pública e justiça, estão ausentes ou não estão sendo eficazes. Observamos que se opera uma compreensão popular de que, embora a justiça oficial exista, ela parece indiferente ao cotidiano ordinário das pessoas pobres. Assim, do mesmo modo como "a Justiça não liga para o povo, o povo não parece ligar para a Justiça", concorrendo para que haja esse aumento da violência cotidiana entre as pessoas, uma prática orientada pela experiência do "fazer justiça com as próprias mãos" ou armar outras mãos para fazê-la. Ou, será que podemos dizer que esses espaços enclaves, no interior da cidade, são lugares em que se permite a eliminação dos sujeitos indesejáveis, matáveis, considerando as relações existentes entre as práticas legais e ilegais dos agentes do Estado, na garantia da ordem e da segurança nesses mesmos espaços? Ou, ainda, não seriam esses espaços da cidade, lugares em que o Estado pode "deixar morrer" e/ou "fazer morrer", como observa uma moradora da periferia de Fortaleza, em depoimento, ao afirmar: "Ali é lugar de matar gente" (Cavalcante, 2011:.58). Ou ainda, o depoimento de um policial - ao ser questionado sobre o elevado número de mortes de jovens de autoria desconhecida na periferia, quando a população dessas áreas conhece as autorias - que disse sem qualquer pudor: "vamos deixar que se matem, cada um que morre é um a menos para nos dar trabalho."

A agudização desse fenômeno tem produzido um quadro de desqualificação nas relações sociais que conformam Fortaleza e fazem parte da memória histórica dos bairros que compõem os lugares periféricos desta cidade. Tanto a polícia, ou a justiça, como os meios de comunicação de massa e parte da sociedade reproduzem estigmas que, de maneira direta ou indireta, concorrem para cristalizar o saber prático da população, associado ao senso comum frente à criminalidade e à violência. Movidos por estas visões, abusos, omissões, imperícias, torturas, abusos de poder, desrespeitos, autoritarismos, julgamentos prévios e discriminatórios, entre outras práticas violentas institucionalizadas, são legitimados conforme a ira pacificadora contra populações excluídas socialmente e previamente consideradas violentas ou culpadas. Ou seja, não se observam escândalos que possam atingir a legitimidade de gestores políticos relacionados à segurança pública, por exemplo, quando "a gente matada" é a "gentalha pobre", negra e sem instrução. A essa gente o "estado de exceção" e/ou o toque de recolher têm sido impostos em muitos bairros da periferia da capital por policiais militares "ciosos" de manter o controle social a qualquer custo.

60 No ano de 2009, uma reportagem de um jornal de grande circulação na cidade foi emblemática na constituição do retrato da problemática em bairros periféricos: "jovens de bairros como Serviluz, Caça e Pesca, Praia do Futuro, Bom Jardim, Canindezinho, Granja Portugal, Parque São Vicente, Luciano Cavalcante e de áreas na Região Metropolitana de Fortaleza, tem o cerco de policiais que fazem suas próprias leis"; a mesma reportagem ouve a população que declara: "Somos uma população amedrontada por policiais corruptos, arruaceiros e terroristas. Uma das coisas é que não se pode mais desfrutar da praça, pois eles chegam expulsando todos que lá estão, mandando irem pra casa"6.

61 Nesses espaços da cidade, quer-nos parecer que os conceitos sujeito matável ou homo sacer , estado de exceção e as configurações embaralhadas entre o legal e ilegal, e ainda, sujeição criminal se realizam, salvo as especificidades da realidade local, na concretude de um "território de exceção" do qual nos fala Cavalcante (2011:72): "trajetórias de vida 
surgem e, ao mesmo tempo, se apagam sob o silêncio de toda uma comunidade". São, assim, as vidas breves dos jovens que engrossam as estatísticas dos homicídios na cidade de Fortaleza.

\section{Algumas reflexões e desafios que continuam postos}

Nesse cenário de violências e crimes, vítimas e vitimizadores, os desafios das políticas públicas de enfrentamento dessa problemática continuam postos. Pesquisadores e gestores públicos consideram que a articulação dos órgãos de segurança pública nos seus níveis local, estadual e federal, é fundamental para elaboração e execução de políticas em interfaces com as demais políticas públicas (especialmente educação e saúde) e a sociedade civil local no enfrentamento mais estratégico da criminalidade e da violência.

Assim, não podemos desconhecer a importância de políticas de intervenção e que estas são de fato necessárias para desafiar e alterar os dados da criminalidade e da violência urbana que atinge a vida de parcela significativa da população jovem da cidade de Fortaleza. Contudo, também sabemos que as políticas utilizam estratégias focalizadas e emergenciais, como discutido acima, e ignoram a estratégia fundamental de serem "políticas de intervenção que tenham sempre por referência o chão que elas pisam, os contextos de vida (objetivos, subjetivos e trajectivos) daqueles a quem elas se dirigem" (Pais, 2010: 141). No que se refere à participação da juventude nestas políticas, a questão fundamental ainda indica uma intervenção quase sempre voltada para uma "educação para o trabalho" colada ao conceito de cidadania normativa e, portanto, definida como "categoria estável de direitos e obrigações". Ainda, para este autor: "raramente essa problematização questiona o sentido do sistema de educação que temos, a desigual estrutura de oportunidades de sistema de emprego..." (ibidem:141-2).

No presente artigo, consideramos pertinente que as políticas públicas respeitem três aspetos: primeiro, o enfrentamento da drogadição e o desarmamento da população, tendo em vista que Fortaleza e seus serviços de saúde, de assistência social e de segurança pública, ainda não contam com diagnósticos precisos sobre a problemática das drogas e, ainda mais, quando associada à utilização de armas de fogo, que lhes possibilitem elaborar políticas públicas de enfrentamento preventivo dessa realidade. Segundo, a criação e a qualificação de ações voltadas para a educação formal ampla de jovens que estão dentro e fora da Escola, não desconsiderando a especificidade de atividades relacionadas com a inserção desses jovens no mercado de trabalho sem, contudo, desvinculá-la de ações voltadas para a aprendizagem crítica de conteúdos gerais, para o acesso aos dispositivos de arte, cultura, desporte e lazer, fundamentais para a inclusão social.

Esses dois primeiros aspetos consideram, enfim, que, sem o enfrentamento dos dispositivos qualificadores da violência, como drogas e armas e sem ampliar condições reais para o alargamento dos horizontes sociais na vida dos jovens, as políticas de juventude tendem a manter-se na superficialidade. Como nos lembra Machado Pais: "[d]esenhar políticas de juventude é desenhar mapas de futuro" (Pais, 2010:142).

o terceiro aspeto diz respeito às práticas ilegais e ilícitas como pano de fundo da problemática aqui abordada. De certa maneira, podemos afirmar que essas práticas acabam por desonerar o Estado da sua responsabilidade de manutenção da ordem social em determinados lugares e espaços da cidade. Tornam-se práticas toleradas e 
incentivadas pela impunidade e, muitas vezes, pelas relações perigosas que envolvem criminosos e homens da lei. Acabam também dando ressignificação aos dispositivos disciplinares de controle e manutenção da ordem nos espaços e lugares da cidade. Ou será que podemos dizer que a segurança não é apenas responsabilidade do Estado, mas também da sociedade, inclusive dos criminosos?

Por fim, que reflexões e ações se apresentam frente ao dimensionamento que assumem as questões vivenciadas pela população dos territórios estigmatizados na cidade de Fortaleza? A discussão pode aprofundar-se nas relações com as organizações da sociedade civil e seus movimentos sociais no poder de articulação e pressão dos seus dispositivos de interlocução com os gestores públicos para horizontalização das políticas públicas nessas áreas, com ênfase na ampliação e integração de políticas e ações setoriais de intervenção de curto, médio e longo prazo. Considerando, ainda, o facto de que a problemática da criminalidade e da violência não se soluciona apenas com ações e intervenções policiais repressivas, são questões que dizem respeito à resolução negociada dos conflitos e tensões da convivência urbana, sem desconhecer as práticas legais e ilegais que dizem respeito à racionalidade da vida em sociedade e de funcionamento dos dispositivos estatais. Portanto, são questões que estão relacionadas com as condições de possibilidades da segurança urbana nas sociedades democráticas, nos seus espaços públicos e na convivência com os diferentes e iguais. Essas são questões que desafiam as agendas dos governos democráticos e lhes impõem o desafio de dialogar com a gramática política dos direitos humanos e discutir os paradigmas de constituição de suas biopolíticas para além das fronteiras do Estado-nação.

\section{BIBLIOGRAFIA}

AGAMBEN, Giorgio (2012), Homo sacer: o poder soberano e a vida nua, Belo Horizonte: Editora UFMG.

AGAMBEN, Giorgio (2004), Estado de Exceção, São Paulo: Boitempo.

AGAMBEN, Giorgio (2008), o que resta de Auschwtiz: o arquivo e a testemunha, São Paulo: Boitempo.

BARREIRA, Cesár. et al. (1999a), Ligado na Galera: Juventude, Violência e Cidadania na Cidade de Fortaleza. Brasília: UNESCO.

BARREIRA, César. et al. (1999b), À Espera de Justiça: assassinatos de crianças e adolescentes na Grande Fortaleza, Fortaleza: Expressão.

BOURDIEU, Pierre (1989) O Poder Simbólico, Rio de Janeiro: Bertrand Brasil.

CALDEIRA, Tereza (2008), Cidades de muros: crime, segregação e cidadania em São Paulo, São Paulo: Ed. 34/Edusp.

CAVALCANTE, Ana Mary (2009), “A lei das esquinas e becos (Especial desvio de conduta)“, Jornal o POVO (Fortaleza), 23 de março: 08.

CAVALCANTE, Ricardo Moura Braga (2011), Vidas breves: investigação acerca dos assassinatos de adolescentes em Fortaleza. Fortaleza, (Dissertação de Mestrado em Políticas Públicas e Sociedade). 
Programa de Pós-Graduação em Políticas Públicas e Sociedade/Universidade Estadual do CearáUECE.

FONSECA, Odemiro (2010), “Quem mata, conhece”, in O Globo.

FOUCAULT, Michel (2008), Nascimento da biopolítica: curso dado no Collège de France (1978-1079). São Paulo: Martins Fontes.

INSTITUTO BRASILEIRO DE GEOGRAFIA E ESTATÍSTICA (IBGE) (2010), Noções básicas de cartografi a.

[online] Disponível em: http://www.ibge.gov.br/servidor_arquivos_geo/ [consultado em: 21 de janeiro de 2010].

INSTITUTO BRASILEIRO DE GEOGRAFIA E ESTATÍSTICA (IBGE) (2009), Malha Digital: referências metodológicas. [online] Disponível em:http://geoftp.ibge.gov.br/mapas/malhas_digitais/ municipio_2005/E500/Documentacao_Tecnica/. [Consultado em 20 de novembro de 2009].

MACHADO DA SILVA, Luis Antônio (2004), "Sociabilidade violenta: por uma interpretação da criminalidade contemporânea no Brasil urbano", Sociedade e Estado. Brasília, v. 19, n.1: 53-84.

MISSE, Michel (2008), "Sobre a construção social do crime no Brasil: esboços de uma interpretação", in M. Misse, Acusados e acusadores: estudos sobre ofensas, acusações e incriminações, Rio de Janeiro: Revan.

MISSE, Michel (2011), “Os rearranjos do poder no Rio de Janeiro”, Le Monde Diplomatique Brasil (Violência urbana), 4, nํ 48: 6-7.

MOTA BRASIL, Glaucíria (2011), «As práticas violentas da polícia e as práticas do "fazer justiça com as próprias mãos": desafios das políticas públicas de segurança na cidade de Fortaleza» in Anais do XV Congresso Brasileiro de Sociologia. [online] Disponível em http://

www.sistemasmart.com.br/sbs2011/arquivos/21_6_2011_12_55_10.pdf. [Consultado em 20 de agosto de 2011].

PAIS, José Machado (2010), Lufa-lufa cotidiana: ensaios sobre cidade, cultura e vida urbana, Lisboa: ICS.

RELATÓRIO DE PESQUISA (2010), Cartografia da Criminalidade e da Violência na Cidade de Fortaleza, Fortaleza: (disponível em www.uece.br/labvida/).

TELLES, Vera da Silva (2010), A cidade nas fronteiras do legal e ilegal, Belo Horizonte: Argvmentvm.

TELLES, Vera da Silva (2011), “A conivência entre o crime e o poder”, Le Monde Diplomatique Brasil (Violência urbana), 4, no 48: 4-5.

TELLES, Vera da Silva (2012), “Jogos de poder nas dobras do legal e ilegal: anotações de um percurso de pesquisa” in C. Azais, G. Kessler, V. Telles (Orgs), Ilegalismos, cidades e política. Belo Horizonte: Fino Traço/Programa de Pós-Gradução em Sociologia-USP.

WACQUANT, Loïc J. D. (2005), As prisões da miséria, Rio de Janeiro: Zahar Editor.

WIEVIORKA, Michel (1997), "O Novo Paradigma da Violência”, in Revista Tempo Social, São Paulo: USP, 9(1): 05-38.

WAISELFISZ, Julio Jacobo (2011), Mapa da Violência no Brasil: os jovens do Brasil, São Paulo: Instituto Sangari, Ministério da Justiça. 


\section{NOTAS}

1. Trata-se da "Pesquisa Cartografia da Criminalidade e da Violência na Cidade de Fortaleza" realizada no ano de 2010, com fi nanciamento do Ministério da Justiça e da Prefeitura Municipal de Fortaleza. O termo cartografi a é definido pela Associação Internacional de Cartografi a (ACI) como um "conjunto dos estudos e operações científicas, técnicas e artísticas que intervêm na elaboração dos mapas a partir dos resultados das observações diretas ou da exploração da documentação, bem como da sua utilização." (IBGE, 2009, p.10).A Pesquisa buscou construir uma base comparativa de dados, compreendendo uma série histórica de 2007, 2008 e 2009 e, por meio da criação de um mapa cartográfico, subsidiar ações dos governos municipal, estadual e federal, bem como da sociedade civil local, voltadas ao enfrentamento da violência e da criminalidade no município de Fortaleza. Acesso ao Relatório completo da Pesquisa nos sites: www.uece.br/labvida e www.uece.br/covio.

2. A pesquisa cartográfica permitiu elencar os bairros que lideraram as estatísticas de homicídio nos ano de 2007 a 2009, sendo aqueles classificados nas vinte primeiras colocações localizados em regiões consideradas de periferia, nos revelando as características da distribuição geográfica desses homicídios. Para conhecimento dos bairros, ver Relatório da Pesquisa Cartografia da Criminalidade e da Violência na cidade de Fortaleza, 2010 e as cartilhas produzidas sobre a realidade de cada bairro em: www.uece.br/labvida.

3. Trata-se da avenida Dom Manuel, localizada na fronteira entre o centro da cidade e os bairros da zona leste, a exemplo dos bairros Aldeota, Meireles, Varjota, considerados nobres, opondo, assim, de forma simbólica, o leste e o oeste de Fortaleza, regiões consideradas pobres e perigosas.

4. Aldeota e Meireles são considerados bairros nobres em Fortaleza e o Iguatemi é o maior e mais frequentado shopping centre da cidade. Exclamações de populares quando tomam conhecimento das ocorrências nos meios de comunicação de massa.

5. No caso do número de homicídios não tão expressivo entre 2007 e 2008, o fato pode está relacionado diretamente ao impacto da criação e implementação do Programa Ronda do Quarteirão, em 2007, no Governo Cid Gomes (2007-2010) e posterior recuo da proposta do Ronda como "policiamento de proximidade com a população", assemelhado ao modelo de policiamento comunitário, na política estadual de segurança pública, associado à saída do Governo do então Secretário de segurança pública, delegado Roberto Monteiro que coordenou a implantação do Programa.

6. Trata-se de matéria sequencial no Jornal O Povo, ou seja, série de reportagens que abordaram a problemática da violência policial, ouvindo reclamações da população de bairros da periferia, especialistas e acadêmicos, além de gestores da segurança pública, que construíram discursos das mais variadas expressões, sejam mais políticos, sejam mais apelativos e mediáticos. Para conferir, ver Jornal O Povo em março de 2009 em: www.opovo.com.br.

\section{RESUMOS}

O presente artigo tem como eixo de discussão a inserção da população jovem nas estatísticas de homicídio na quinta capital brasileira e como quadro de referência a análise do que se denomina de espaços urbanos estigmatizados e embaralhados, e demarcados por fronteiras porosas. São 
questões ancoradas em discussões sobre estigma territorial, sujeição criminal, estado de exceção, onde se discutem espaços de vida e de morte e políticas públicas enveredadas nessa cidade fronteiriça, que se constitui por relações de poder tecidas em redes que operam por práticas formais e informais, legais e ilegais, lícitas e ilícitas e, portanto, demarcada por "fronteiras porosas".

This article is discussing the insertion axis of the youth population in the statistics of homicides on Thursday as the Brazilian capital and framework analysis of what is called urban spaces stigmatized and shuffled and marked by porous borders. Questions are anchored in discussions about territorial stigma, criminal liability, state of exception, where we discuss spaces of life and death and public policy get in this border city, which is constituted by power relations woven into networks that operate by formal practices and informal, legal and illegal, licit and illicit, and therefore marked by "blurred boundaries".

Cet article a comme axe de discussion l'insertion de la population des jeunes dans les statistiques d'homicides à Fortaleza et est analyse dans un cadre qu'on appelle les espaces urbains stigmatisés et mélangées et marquée par la porosité des frontières. Les questions sont ancrées dans les discussions sur la stigmatisation territoriale, la responsabilité pénale, l'état d'exception, où nous discutons des espaces de vie et de mort et les politiques publiques dans cette ville frontalière, qui est constitué par les relations de pouvoir tissés dans les réseaux qui opèrent par des pratiques formelles et informelles, légale et illégale, licites et illicites, et donc marquée par des «frontières floues».

\section{ÍNDICE}

Palavras-chave: estado de exceção, políticas públicas, homicídios de jovens

Keywords: state of exception, public policy, youth homicides

Mots-clés: état d'exception, politique publique, homicides chez les jeunes

\section{AUTORES}

\section{GEOVANI JACÓ DE FREITAS}

Professor adjunto da Universidade Estadual do Ceará (UECE) e coordenador do Laboratório de Estudos da Conflitualidade e da Violência (COVIO)

giljaco@uol.com.br

\section{GLAUCÍRIA MOTA BRASIL}

Professora adjunta da Universidade Estadual do Ceará (UECE) e pesquisadora do CNPq glaumota@cnpq.br

\section{ROSEMARY DE OLIVEIRA ALMEIDA}

Professora adjunta da Universidade Estadual do Ceará (UECE) e editora da Revista 0 público e o privado rosemary.almeida@uol.com.br 